|| Print ISSN: 2589-7837 || Online ISSN: 2581-3935 ||

International Journal of Medical Science and Diagnosis Research (IJMSDR)

Available Online at www.ijmsdr.com

NLM (National Library of Medicine ID: 101738824)

Original Research Article

Volume 5, Issue 3; March: 2021; Page No. 05-09

\title{
ULTRASOUND CORRELATION OF PLACENTA PREVIA IN ANC FEMALES WITH PREVIOUS LSCS PREGNANCIES
}

\author{
Dr. Ojaswi B Khandediya ${ }^{1}$, Dr. Priti Kapoor ${ }^{2}$, Dr. Vishal Singh ${ }^{3}$ \\ ${ }^{1}$ Resident in Department of Radiodiagnosis, MGM Medical College and Hospital, Navi Mumbai \\ ${ }^{2}$ Professor and HOD of Radiodiagnosis, MGM Medical College and Hospital, Navi Mumbai \\ ${ }^{3}$ Senior Resident in Department of Radiodiagnosis, MGM Medical College and Hospital, Navi Mumbai
}

Conflicts of Interest: Nil

Corresponding author: Dr. Ojaswi B Khandediya

DOI: https://doi.org/10.32553/ijmsdr.v5i3.768

\section{Introduction:}

The placenta is a highly specialized tissue that serves a number of crucial functions for survival of the foetus. It allows the foetus to receive oxygen and nutrition before it can breathe or nourish itself. The placenta releases multiple hormones that initiate and maintain the essential changes of pregnancy in both the mother and the foetus. $(1,2)$ The normal human placenta averages $22 \mathrm{~cm}$ (9 inch) in length and 2-2.5 cm (0.8-1 inch) in thickness, with the center being the thickest, and the edges being the thinnest. It typically weighs approximately 500 grams $(1 \mathrm{lb})$. It has a dark reddishblue or crimson color. It connects to the fetus by an umbilical cord of approximately 55-60 cm (22-24 inch) in length, which contains two umbilical arteries and one umbilical vein. The umbilical cord inserts into the chorionic plate (has an eccentric attachment). Abnormalities in the placenta raise concerns not only for the healthy growth of the foetus but also the antenatal and perinatal health status of the mother. (46 ) It has been observed that survival and growth of the fetus is affected by different aspects of the placental morphology, and its efficient functioning. Different factors affect the placental morphology and physiology. During pregnancy, complications like hypertension and gestational diabetes make changes in the placenta.(10-13) A previous surgery makes the next pregnancy vulnerable to different complications due to the associated post-operative changes in the uterus. Careful examination of the placenta 3 can give information which can be useful in the management of complications in the mother and the fetus.(3) Hence sonography has a large role to play in the screening of the placenta to be able to preempt possible complications. Thereby the Radiologist can help the clinician to be better prepared to handle complications efficiently. Obstetrical haemorrhage continues to be an important cause of maternal mortality, accounting for
$15-20 \%$ of maternal deaths. Recent epidemiological studies have also found that the strongest risk factor for Abnormal Trophoblastic invasion is a previous LSCS where a failure of decidualisation in the area of a previous uterine scar can have an impact on both implantation and placentation.[14] The absence of Decidua Basalis precludes to abnormal villous migration/adherence in this region. The incidence of LSCS has been rising [15] in the past 3 decades. With the increased number of Caesarean sections, the number of pregnancies with previous LSCS rises as well. Abnormal placentation can result in life threatening maternal complications [16-18] such as haemorrhage and shock and increased number of cases of Caesarean Hysterectomies. Also seen, is an increase in adverse infant outcomes such as prematurity, still birth and neonatal death.

\section{Aim and objective}

To assess the placental morphology in pregnancies with Previous LSCS and find out the association between abnormal placental morphology and pregnancy outcome in pregnancies with Previous LSCS with selected demographic variables. The study also aims to establish the association between placenta previa and abnormal trophoblastic invasion and study the Maternal \& Foetal outcomes in cases of abnormal placentation.

\section{Material and method}

It is a prospective study conducted on 50 ANC females with previous LSCS pregnancies reporting to Department Of Radiodiagnosis between Gestational Age of 18-32 Weeks and who are willing for the study and available for follow-up. All patients were registered strictly adhering to the Guidelines of PCPNDT Act. Ultrasound scanning was used for all the ladies in the study group. Thus cases with low lying placentae and any other abnormality were 
followed-up with repeat ultrasound scans throughout the pregnancy while those diagnosed to have normal placentae were followed up only for the outcome. The grey scale real time ultrasonographic examinations were performed using GE Voluson P8 machine. The transducer used for the study was a $3.5 \mathrm{MHz}$ curvilinear array transducer, Linear array $7.5 \mathrm{MHz}$ and Tranvaginal $6.5 \mathrm{MHz}$ array SOS,. Hard copy images of the cases were acquired using thermal printer and photographs.

\section{Results}

A prospective study of all pregnancies with previous history of Lower Segment caesarean Section reporting for Obstetrics Ultrasound at the Obstetric Unit of the tertiary care centre from December 2019 to October 2020 was done. A total number of 100 pregnancies with previous history of Lower Segment caesarean Section were evaluated during the same period. Total number of normal placentation in these cases was 83( $83 \%$ ) and incidence of placenta previa was $17(17 \%)$.In the study group of 100 patients, 57 patients had previous $1 \mathrm{CS}, 31$ previous $2 \mathrm{CS}$ and 12 had previous $3 \mathrm{CS}$. Maximum number of placenta previa cases were in the age group of 20-24 which is the period corresponding to the maximum fertility and also represents the greatest proportion of population in our study. In this study majority that is a total number of $56(56 \%)$ pregnancies were in the age 44 group of 20-24, of which $9(52.9 \%)$ were in pregnancies with abnormal placentation and 47(56.6) in pregnancies with normal placentation. $10(10 \%)$ pregnancies were in age group. Out of 17 placenta previa - 2 had malpresentation and 15 had normal presentation. 3 out of 83 normal placentation had malpresentations and 80 had normal presentation. The risk of breech presentation is 3.2 times higher in placenta previa compared to normal placentation and it is statistically significant. Out of the total of 17 placenta previa 2 had anomalies that is $11.8 \%$ and 15 were normal that is $88.2 \%$. Among the normal placentation 3( 3.7\%) cases were found to have anomalies and 80 cases( $96.3 \%$ ) were normal. The risk of getting anomalies is around 4 times higher among the placenta previa cases than normal placentation. Radiologically 12 patients were diagnosed as Placenta Previa without adherent placenta that is $12 \%, 3$ were diagnosed as Placenta Percreta which was $3 \%$ and 2 were diagnosed as Placenta Previa with acreta that is $2 \%$. Intraoperatively, 10 patients had placenta previa without adherence, 5 placenta percreta, and 4 with placenta previa with Acreta. Out of 17 cases, 6 (35.2\%) had
Type I-Placenta Previa, 2 had Type II-Anterior placenta which was about $11.7 \%, 1$ had Type IIposterior placenta about 5.8\%, 4 had Type III placenta which was around $23.52 \%$ and 4 cases were of Type IV placenta previa which was about $23.52 \%$. Out of total 17 cases 8 cases had minor degree of placenta previa and 9 cases major degree. Out of 17 cases of placenta previa 3 pregnancies had 1 previous history of Lower Segment caesarean Section that is $17.64 \%$, majority that is 10 had 2 previous history of Lower Segment caesarean Section which is $58.8 \%$ and 4 had 3 previous 52 history of Lower Segment caesarean Section which is about $23.5 \%$ Among 83 cases of normal placentation 54 had 1 previous history of Lower Segment caesarean Section which is about $65.3 \%, 21$ had 2 previous history of Lower Segment caesarean Section that is $25 \%$ and 8 had 3 previous history of Lower Segment caesarean Section which is about $9.63 \%$. Previous 2 cesarean section has around 2.3 times higher risk of placenta previa in subsequent pregnancy than those without it. In our study Uterine Dehiscence/Rupture was seen in a total of $5(5 \%)$ cases out of which 2 cases were from pregnancies with abnormal placentation which is about $11.76 \%$ and 3 cases from pregnancies with normal placentation which is about $3.61 \%$ In our study, uterine artery ligation was done in $41.18 \%$ of pregnancies with abnormal placentation that is 7 cases and $8.43 \%$ cases of normal placentation that is 7 cases, $5.88 \%$ cases of abnormal placentation that is 1 and $18.07 \%$ cases of normal placentation that is 15 cases required internal iliac ligation and similar number required obstetric hysterectomy. 55 In our study placenta was kept in situ for 3 patients of abnormal placentation that is $17.65 \%$. A total of $5(5 \%)$ cases required ICU admission out of which 2 pregnancies were with abnormal placentation that is $11.76 \%$ and 3 pregnancies were with normal placentation that is $3.61 \%$ A total of 20 patients $(20 \%)$ had surgical site infections in our study group. 52.94\% of cases with abnormal placentation had surgical site infection that is 9 cases and $13.25 \%$ of normal placentation that is 11 cases. Majority of them required $(77 \%)$ required secondary suturing and $23 \%$ had healed with secondary intention. In our study, 14 neonates (14\%) required resuscitation. $35.29 \%$ (6) neonates born of mother with abnormal placentation required resuscitation whereas $9.64 \%$ (8) of neonates born of mother with normal placentation required resuscitation. $18 \%$ (18) of neonates in our study required neonatal intensive care unit (NICU) admissions. Out of 17 neonates born of mother with 
abnormal placentation $7(41.18 \%)$ required NICU admission and 11(13.25\%) neonates born of mother with normal placentation required NICU admission.

\section{Discussion}

The rate of Caesarean delivery has been increasing steadily over the past two decades and is the most common obstetric operative procedure worldwide. Some studies have observed an increase in the frequency of placental location abnormalities among women with history of prior Caesarean deliveries. Bender first suggested that a uterine scar could predispose the mother to the development of placenta praevia in subsequent pregnancies. (17) Recent studies by Clark et al (18) and Rose and Chapman (19) have confirmed the significant relationship between placenta praevia and previous CS. Placenta praevia is strongly associated with placenta accreta. The incidence of placenta accrete is as high as $67 \%$ in patients with placenta praevia and multiple previous CS. This association of previous CS, placenta praevia and plaqenta accrete is becoming increasingly acknowledged and is causing concern since it carries a significant risk of caesarean hysterectomy with its incumbent morbidity and mortality (20) . Bellala Swetha (21) reported that most of the patients ranged between 20-30 years of age. Median age was 27 years which is approximately similar to our study. Z Parvin et al (22) revealed that the mean age of the patients was 27.25 \pm 3.43 years with maximum number of patients having age between 25 to 29 years. Placenta Praevia is the partial or full attachment of placenta in lower uterine segment. The relationship of placenta praevia and number of previous caesarean section was assessed in this cross-sectional type of study. Many studies conducted around the world confirm a 2 to 5 fold increased risk of placenta praevia with previous history of c-section. Ultrasonographic and peroperative findings were found similar in all cases in this study. Incidence of placenta praevia after one caesarean section was $17 \%$ which is much higher than that in a study of Clark and colleagues which showed $0.67 \%$ (23). It was confirmed that previous caesarean section increases the risk of placenta praevia and the risk is proportional to the number of previous uterine scars. The study conducted by Nielson 80 showed risk of placenta praevia $1.22 \%$ which is much less than our study. The results are also comparable to study of Cande (24) which showed increased number of placenta praevia with increasing number of caesarean deliveries. Usta et al (25) conducted study in 347 placenta praevia cases. One of the factors highly associated with Placenta praevia was previous CS, where the rate of PP increased with the number of previous caesarean sections. The risk for $\mathrm{PP}$ in patients with one CS was 8- fold higher compared with those with an unscarred uterus that is $1.9 \%$ with one prior caesarean section and $15.6 \%$ with two prior caesarean sections(25). Pathological changes in the myometrium and endometrium of the uterus have been described in the presence of previous cesarean delivery scar. These include polyp formation, lymphocyte infiltration, capillary dilatation, and infiltration of the endometrial tissue that surround the scar by free red blood cells. These observations suggest that the pathological changes in the vicinity of cesarean delivery scars may create suboptimal implantation of the placenta, increased vascular malformations, and increased fragility of vessels that are known risk factors for abruption. Furthermore, rupture of the spiral arteries may lead to the formation of decidual hematomas, which may likely culminate in placental abruption. The same pathological changes of the endometrium and uterine cavity may be responsible for the increased risk of placenta previa among women with prior caesarean delivery. Tayyaba Majeed et al (26) in their study revealed that 67 patients were between G2-G4, 42 between G5-G7, and 5 were more than G7. Tayyaba Majeed et al in their study reported that out of 114 cases of placenta Previa, 18 had history of previous one LSCS, 26 had two LSCS, 29 had three LSCS, and 4 had previous four LSCS. The frequency of placenta Previa found in previously scarred uterus was $5.70 \%$, while it was $10.67 \%$ in non scarred uterus. Based on the results of the present study, it can be said that a cesarean birth is an important risk factor for placenta previa and placental abruption in a subsequent pregnancy. The presence of a dose-response pattern in the risk of placenta previa with increasing number of prior cesarean deliveries, coupled with a biologically plausible association, provides compelling evidence in support of the association. Irrespective of the method of delivery in the first pregnancy, a short interpregnancy interval appears to be associated with increased risks of both placenta previa and placental 65 abruption. The effects of these associations on adverse pregnancy outcomes remain unknown.

\section{Conclusion}

It can be concluded that in our study population the caesarean section had a significant relationship with placenta praevia and this risk becomes very high with escalation in number of caesarean sections. There is a 
strong association between previous LSCS and risk of subsequent development of placenta praevia. The study also reinforces the importance of advocating vaginal delivery as far as possible and reduces the number of LSCS and future placenta praevias. Women with previous LSCS scar are at high risk for developing placenta praevia in subsequent pregnancy. The nature of placenta previa can be unpredictable and harsh on the mother and baby. So, Careful monitoring of high risk pregnancies is of utmost importance. Avoidance of unnecessary caesarean sections and early week's pregnancy terminations can minimize the Obstetricians' nightmare.
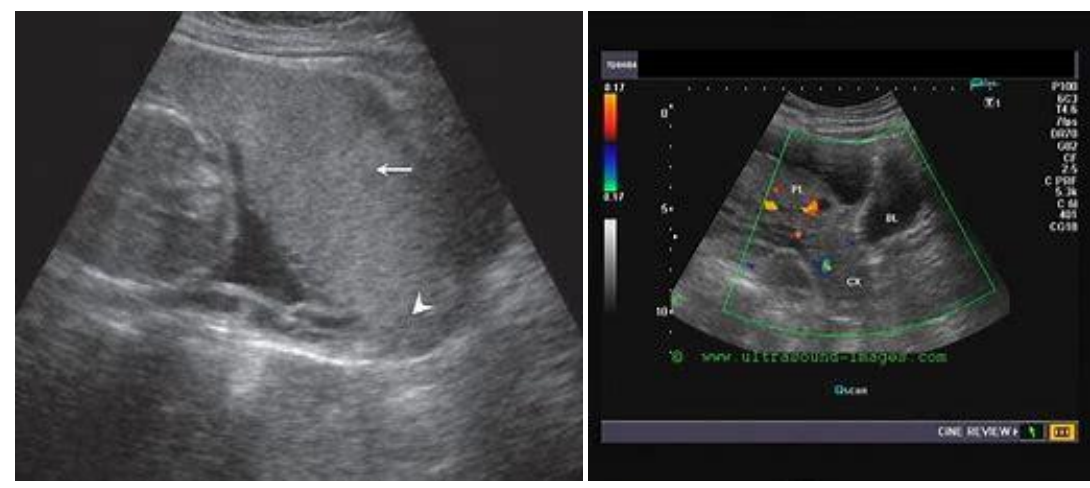

Figure 1: Gray scale and doppler ultrasound showing low lying placenta completely covering the internal os of cervix.

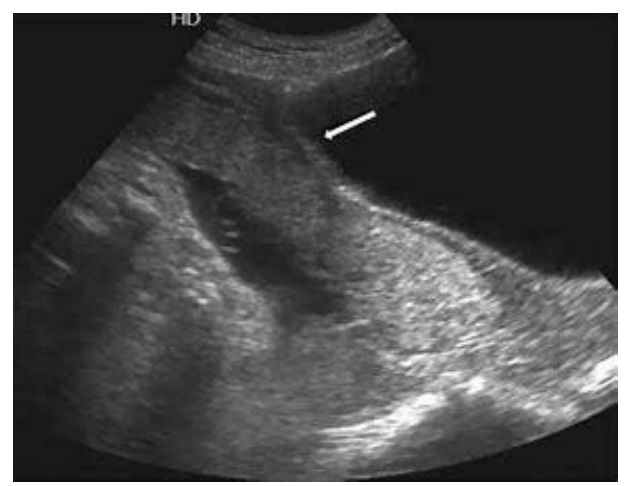

Figure 2: Gray Scale ultrasound showing low lying placenta $2.5 \mathrm{~cm}$ from the internal os.

\section{References}

1. Placenta: From Wikipedia, the free encyclopedia, Available from http://en.wikipedia.org/w/index.php?title=Place nta\&oldid=586394729

2. Helen swan, placenta- mother of us all, 2007, available from http://www.naturalhealthanswers.co.uk/archives 071.php

3. Pradeep S Londhe and Abhay B Mane, morphometric study of placenta and its corelation in normal and hypertensive pregnancies, International Journal of Pharma and Bio Sciences, 2011, oct- dec, vol 2, issue

4. Available from http://www.ijpbs.net/vol2_issue-4/bio_science/48.pdf
5. Jenny A. Cresswell, Carine Ronsmans, Clara Calvert and Veronique Filippi. Prevalence of placenta previa by world region: a systematic review and meta - analysis.Tropical Medicine and International Health 2013 Jun; 18(6):71224.

6. Ananth CV, Smulian JC \& Vintzileos AM. The association of placenta previa with history of cesarean delivery and abortion: a meta analysis. Am J Obstet Gynecol. 1997 Nov;177(5):10718.

7. Faiz AS, Ananth CV: Etiology and risk factors for placenta previa: an overview and metaanalysis of observational studies. J Matern Fetal Neonatal Med 2003 Mar; 13(3):175-90.

8. Gurol-Urganci I, Cromwell DA \& Edozien LC et all.Risk of placenta previa in second birth 
after first birth cesarean section: a population based study and meta-analysis. BMC Pregnancy Childbirth. 2011 Nov 21; 11: 95. doi: 10.1186/ 1471-2393-11-95.

9. Liang-kun, Na N, Jian-Qiu Y, Xu-Ming B, JunTao L. Clinical analysis of placenta previa complicated with previous caesarean section. Chin Med Sci J.2012 Sep; 27(3):129-33. 68

10. Gallagher P, Fagan CJ, Bedi DG, Winsett MZ, Reyes RN. Potential placenta previa: definition, frequency and significance. Am J Roentgenol. 1987 Nov; 149(5):1013-5.

11. Anderson ES, Steinke NMS.The clinical significance of asymptomatic midtrimester low placentation diagnosed by ultrasound. Acta Obstet Gynecol Sc and. 1988; 67(4):339-41.

12. Taipale $P$, Hiilesman V,Ylostalo P.Transvaginal ultrasonography at $18-23$ weeks in predicting placenta previa at delivery.Ultrasound Obstet Gynecol. 1998 Dec;12(6):422-5.

13. Mustafe SA, Brizot ML, Carvelho MHB, Watanabe L, Kahhale S,Zugaib M. Transvaginal ultrasonography in predicting placenta previa at delivery: a longitudinal study.Ultrasound Obstet Gynecol. 2002 Oct;20(4):356-9.

14. Jauniaux E, Jurkovic D.Placenta accreta: pathogenesis of a 20th century iatrogenic uterine disease.Placenta.2012 Apr; 33(4):24451.

15. Milosevic J, Lilic V, Tasic M, Antic V.Placental complications after a previous cesarean section.Med PREGL.2009 MayJun;62(5-6):212-6.

16. Crane JM, Van den Hof MC, Dodds L, Armson BA\& Liston R. Neonatal outcomes with placenta previa.Obstet Gynecol.1999 Apr;93(4): 541-4.

17. Crane JM, Van den Hof MC, Dodds L, Armson BA\& Liston R. Maternal complications with placenta previa.Am J Perinatol.2000;17(2):1015 .

18. Bahar A ,Abusham A, Eskandar M, Sobande A\& Alsunaidi M. Risk factors and pregnancy outcome in different types of placenta previa.J Obstet and Gynaecol Can.2009 Feb;31(2):12631.
19. W. W.K. To, W.C. Lmng / International Journal of Gynecol

20. Clark SL, Koonings PP, Phelan JP. Placenta praevia/accrete and prior caesarean section. Obstet Gynecol 1985;66: 89-92.

21. Rose G, Chapman MG. Aetiologic factors in placenta praevia. A casecontrolled study. $\mathrm{Br} \mathbf{J}$ Obstet Gynaecol 1986; 93: 586-588.

22. Breen JL, Nuebecker R, Gregori CA. Placenta accreta, increta and percreta. A survey of 40 cases. Obstet Gynecol 1977; 49: 43-47.

23. Faiz AS, Ananth CV. Etiology and risk factors for placenta previa: an overview and metaanalysis of observational studies. J Matern Fetal Neonatal Med 2003;13:175-90.

24. Ananth CV, Smulian JC, Vintzileos AM. The association of placenta previa with history of cesarean delivery and abortion: metaanalysis. Am J Obstet Gynecol 1997;177:1071-8.

25. Swetha B. Study on Association of Placenta Previa with Previous Cesarean Section Pregnancy. IOSR Journal of Dental and Medical Sciences (IOSRJDMS) 2016;15(5):6063.

26. Parvin Z, Das S, Naher L, Sarkar SK, Fatema K. Relation of Placenta Praevia with Previous Lower Segment Caesarean Section (LUCS) in our Clinical Practice. Faridpur Medical College Journal. 2017;12(2):75-7.

27. Majeed T, Waheed F, Mahmood Z, Saba K, Mahmood H, Bukhari MH. Frequency of placenta previa in previously scarred and non scarred uterus. Pakistan journal of medical sciences. 2015;31(2):360.

28. Nielsen TF, Hagberg H, Liungblad U. Placenta previa and antepartum haemorrhage after previous caesarean section. Obstet Gynecol. 1989; 27: 88-90. 75

29. Cande V, John C, Anthony M. The association of placenta previa with history of caesarean delivery and abortion: A metaanalysis. Am J Obstet Gynecol. 1997; 177:1071-78.

30. Usta IM, Hobeika EM, Musa AA, Gabriel GE, Nassar AH. Placenta previaaccreta: Risk factors and complications. Am J Obstet Gynecol. 2005; 193:1045-9 